\title{
SEDENTISM AND MALNUTRITION AMONG NOMADIC FULANI CHILDREN IN SOUTH WESTERN NIGERIA
}

\author{
Ekpo UF ${ }^{1}$ Omotayo $\mathrm{AM}^{2}$ and MA Dipeolu ${ }^{3}$
}

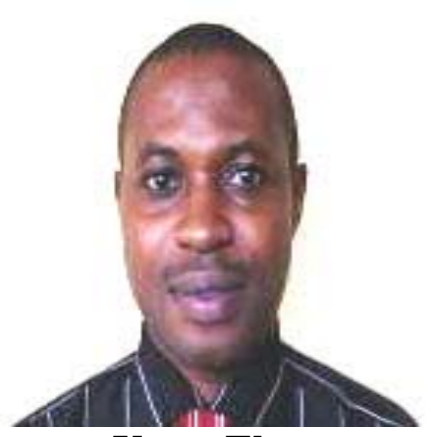

Uwen Ekpo

*Corresponding author email: ufekpo@ @otmail.com

${ }^{1}$ Department of Biological Sciences, University of Agriculture, Abeokuta, Nigeria ${ }^{2}$ Department of Agricultural Extension and Rural Development, University of Agriculture, Abeokuta, Nigeria

${ }^{3}$ Department of Veterinary Public Health, College of Veterinary Medicine, University of Agriculture, Abeokuta, Nigeria 


\section{ABSTRACT}

Studies on the health, nutrition and growth of nomadic Fulani children are rare. In recent times, the nomadic Fulani of Northern Nigeria are gradually migrating and settling in the southern part of the county. The effect of these changes from nomadic to sedentary living is not known, particularly the effects on nutrition and development of their children. Therefore, a cross-sectional study on the nutrition and growth of Fulani children, aged six months to 15 years, living in Kwara, Ogun and Oyo States of South western Nigeria was conducted between March 2003 and December 2004. This population of Fulani are fully settled nomads whose economy and culture are now centred on cattle and farming. There is a dearth of information on the prevalence of malnutrition in this group. The heights and weights of 164 girls and 167 boys were measured, to determine their anthropometric indices, height-for-age (HA), weight-forheight (WH), and weight-for-age (WA) Z-scores. The prevalence of stunting (HAZ < -2 ), wasting (WHZ <-2) and underweight (WAZ <-2) was 38.7\%, 13.6\%, and $38.7 \%$, respectively when compared to the reference National Centre for Health Statistics and World Health Organization (NCHS/WHO) standard used for defining stunting, wasting and underweight. Boys were more malnourished than the girls, but this was not statistically significant (stunting: $\chi^{2}=0.36 ; \mathrm{df}=1 ; \mathrm{P}=0.54$ ); (underweight: $\chi^{2}=1.10 ; \mathrm{df}=1 ; \mathrm{P}=0.29$ ); and (wasting: $\chi^{2}=0.00 ; \mathrm{df}=1 ; \mathrm{P}=0.98$ ). Using World Health Organization Malnutrition Classification systems, $38.7 \%$ of the children were found to be malnourished. It was concluded that malnutrition among the pastoral Fulani children could be linked to changes in food habits, which may be as a result of transition from a nomadic to sedentary lifestyle. It is suggested that food supplements, nutritional and health education programme should be introduce in pastoral Fulani settlements as a first step to improving the nutritional and growth of settled pastoral Fulani children.

Key words: Internal migration, malnutrition, Fulani, Nigeria. 


\section{INTRODUCTION}

The nomadic Fulani of Northern Nigeria migrating into the Southwest are gradually becoming sedentary [1]. Throughout the region of south western Nigeria, Fulani settlements are expanding and in some cases resulting in conflicts with host communities [2]. The change from nomadic lifestyle to full sedentary lifestyle is generating changes in their living conditions, food habits, nutrition and health [3]. The trend of these changes suggests consequences for child health and nutrition as malnutrition arising from both change in food habits and possible inequitable distribution of food within families, although yet undocumented. Studies on the health of nomadic Fulani groups are scanty [4], while the increasing evidence of ill-health, morbidity and mortality in this group calls for the need to provide them with modern health care services [5,6]. Although the nomadic Fulani are responsible for the provision of animal meats in countries where they are found, their welfare has been largely ignored by government [6]. Apart from the studies among semi-nomadic Fulani children in northern Nigeria there is no information on the nutritional status of semi-nomadic Fulani children living in south western Nigeria [7]. It is known, that child growth and health in any population depend among others on both the quantity and quality of nutrition, sanitation and living condition. This study, therefore, describes the nutritional status of these children due to changes from nomadic to seminomadic lifestyle.

\section{MATERIALS AND METHODS}

\section{Study Area}

The study was carried out in three states located in the south western region of Nigeria. The three states are Ogun, Oyo and Kwara. The three states lie between Latitude $7^{\circ} 01^{\prime} \mathrm{E}$ and $8^{\circ} 14^{\prime} \mathrm{E}$ and Longitude $2^{\circ} 45^{\prime} \mathrm{N}$ and $4^{\circ} 15^{\prime} \mathrm{N}$. Oyo and Ogun states are located in humid zone, while Kwara state is in sub-humid zone. The three states were selected because it has been established that a large number of nomadic Fulani are living either in grazing reserves or in other locations selected by the Fulani themselves [1]. The area is inhabited mainly by the Yoruba. Kwara State has a large number of other indigenous tribes which includes a sub-cultural group of Fulani who speak Yoruba as well as Fulfude. The area has a wide range of vegetation zones. The vegetation ranges from fresh water swamp with mangrove forest in the southeast part of Ogun State through diverse forest communities to the woody Guinea and Sudan savannah in the Northern parts of Oyo and Kwara States. Rainforest now turned disturbed forest, covers a considerable portion of Oyo and Ogun States. A vast portion of the land area in Oyo and Kwara is made up of savannah woodland. The vegetation is dictated mainly by the rainfall pattern. Rainfall ranges from $900 \mathrm{~mm}$ in the northern parts of Kwara State, to $1600 \mathrm{~mm}$ along the coastal areas of Ogun State. Humidity in the region is between 70 and $95 \%$ (Fig 1). 
Figure 1: $\quad$ Map of South western Nigeria showing location of Fulani Settlements in Kwara, Ogun and Oyo State (Nigeria inset)

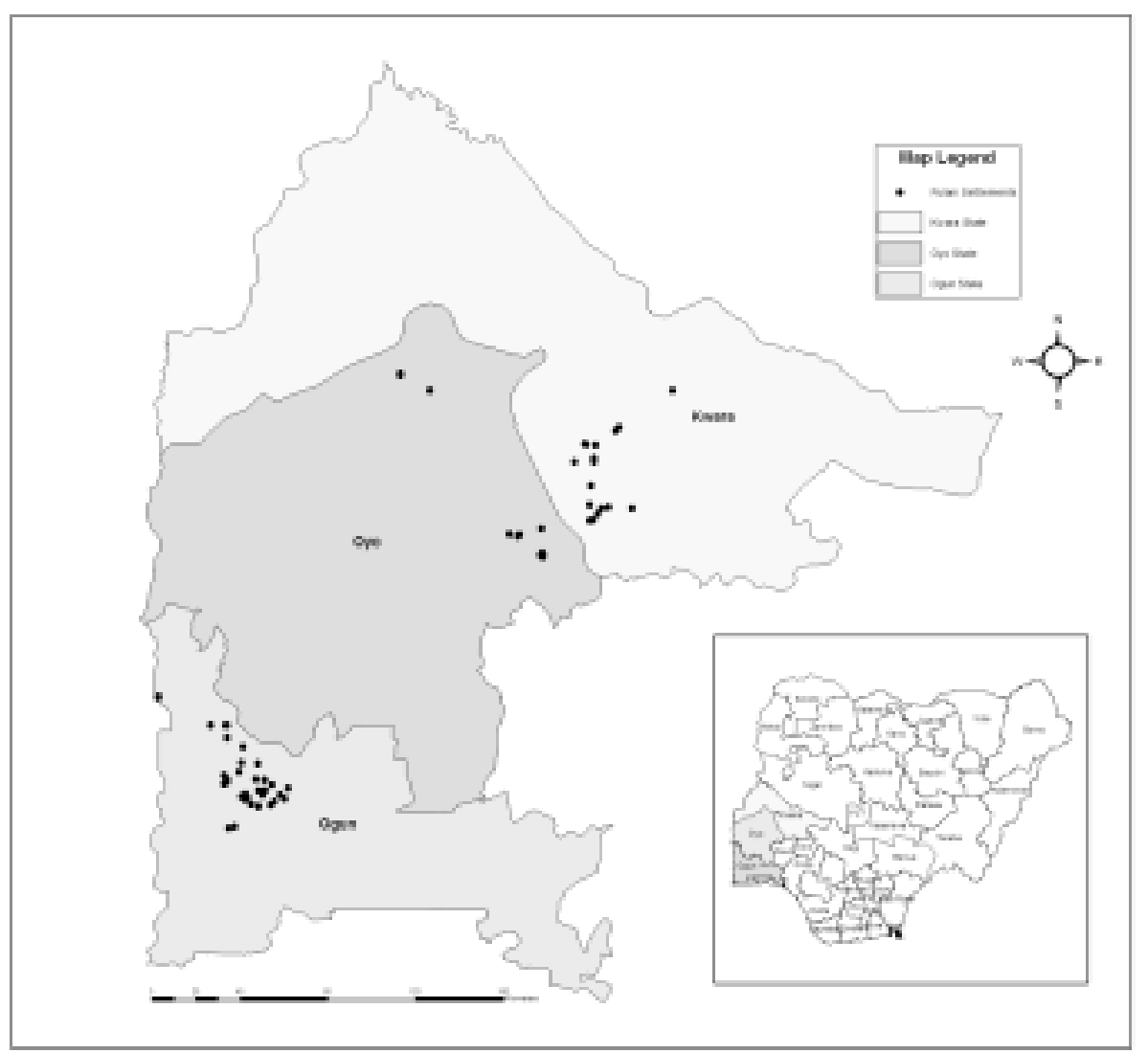

\section{Anthropometric measurements}

Between March 2003 and December 2004, cross-sectional surveys were conducted in Fulani's settlements as part of a larger study to access the health consequences of lifestyle changes among pastoral populations in southwest Nigeria. During this period anthropometry measurements were taken from Fulani children aged six months to 15 years in 61 settlements cutting across the three states. Measurements were performed according to standard procedures of the World Health Organization [8]. Children were weighed wearing light clothes only, and they were measured using a digital scale accurate to $0.5 \mathrm{~kg}$ and height was measured to within $0.25 \mathrm{~cm}$ using a portable Stadiometer [9]. Ages of children were obtained from their parents or caregivers or sometimes calculated using local events, which could be dated, and linked to important life history episodes. The Z-scores for height-for-age (HAZ), weight-forheight (WHZ) and weight-for-age (WAZ) were calculated using reference data from the World Health Organization and United States National Centres for Health Statistics [10] in EPI-Info for windows (nutrition program) software, version 3.4.3 from Centres for Disease Control and Prevention, Atlanta, GA. Children were classified as stunted, wasted or underweight if their HAZ, WHZ or WAZ was $<-2$, respectively. Severely malnourished children were referred to the local health centre 
near the settlement for care. Other analyses are presented as percentage, mean and standard deviation (SD).

The study was reviewed and approved by the institutional ethical review board of the University of Agriculture, Abeokuta, Nigeria. Written informed consent was obtained from parents or caregivers for each child.

\section{RESULTS}

A total of 331 settled pastoral children comprising of 167 (50.5\%) boys and 164 (49.5\%) girls were assessed in Kwara, Oyo and Ogun States. The overall prevalence of stunting was $38.7 \%$, underweight $38.7 \%$ and wasting $13.6 \%$. Boys were more malnourished than the girls, but this was not statistically significant (stunting: $\chi^{2}=0.36 ; \mathrm{df}=1 ; \mathrm{P}=0.54$ ); (underweight: $\chi^{2}=1.10 ; \mathrm{df}=1 ; \mathrm{P}=0.29$ ); and (wasting: $\chi^{2}=0.00$; $\mathrm{df}=1 ; \mathrm{P}=0.98)$ (Table 1).

Low height-for-age was highest in 12-23 months age group where $83.3 \%$ of children in this age group were stunted. Forty-two point nine percent (41.9\%) of the boys had a low height-for-age or were stunted, while $35.4 \%$ of the girls were stunted. There was no significant difference in low height-for-age between boys and girls $(\mathrm{P}=0.547)$. The highest prevalence of stunting of $83.3 \%$ was observed among 12-23 months age group, while the lowest of $15.8 \%$ was seen in the $84-95$ months age group. There were significant differences in stunting among the age groups $(\mathrm{P}<0.0005)$ (Table 2$)$.

Low weight-for-age was also highest in $12-23$ months age group where $75.0 \%$ of the children in this age group were underweight. Forty-three point one percent $(43.1 \%)$ of the boys had a low weight-for-age or were underweight, compared to $34.1 \%$ of the girls. The highest prevalence of underweight of $75.0 \%$ was also observed among 1223 months age group, while the lowest of $16.1 \%$ was seen in the $48-59$ months age group (Table 3 ).

Low weight-for-height was highest in $72-83$ age groups where $25.6 \%$ of children in this age group were wasting. Fourteen point five percent $(14.5 \%)$ of the children were wasting. It also shows that $17.2 \%$ of the boys had a low weight-for-height, compared to $11.9 \%$ of the girls. The highest prevalence of wasting of $25.6 \%$ was recorded in $72-$ 83 months age group, while the lowest of $3.8 \%$ was seen in the $36-47$ months age group (Table 4).

Overall, the variations in nutrition indicators within age groups was significantly different for Height-for-Age $\left(\chi^{2}=35.802 ; \mathrm{df}=10 ; \mathrm{P}<0.005\right)$ and Weight-for-Age $\left(\chi^{2}=40.254 ; \mathrm{df}=10 ; \mathrm{P}<0.0005\right)$ but not significantly different for Weight-for-Height $\left(\chi^{2}=10.413 ; \mathrm{df}=10 ; \mathrm{P}=0.405\right)$.

The mean of Z-scores of Height-for-age, Weight-for-age and Weight-for-height in the study population were $-1.502,-1.634$ and -0.931 respectively. The SD was $1.52,1.09$ and 1.20 , respectively. Comparing these values to mean and standard deviation of Zscores of the WHO/NCHS reference population of 0.00 and 1.0, suggests a high 


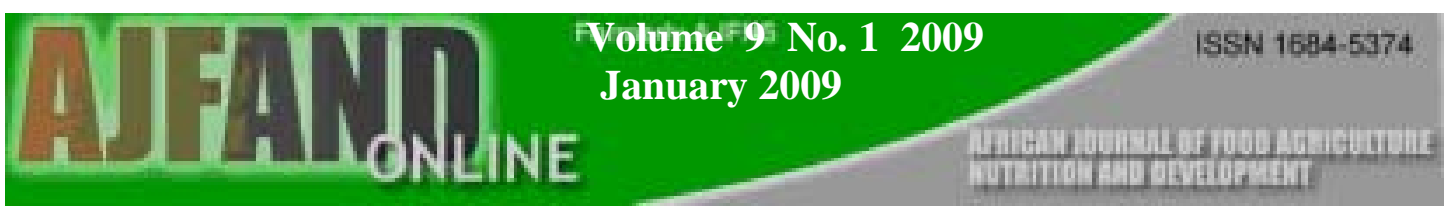

prevalence of malnourishment in the population. In a standard population only $2.3 \%$ of the population are expected to fall below -2SD Z-score. Using WHO Malnutrition Classification systems, $38.7 \%$ of the children were found to be malnourished.

\section{DISCUSSION}

Nutrition among the nomadic Fulani of Nigeria is traditionally based on milk and dairy products complemented by grains obtained from trade or agro-pastoral production [11]. This study observed a high level of malnutrition of $38.7 \%$ among settled nomadic Fulani children in Southwest Nigeria. Malnutrition in semi-nomadic Fulani children reported from the Northern part of Nigeria suggests that malnutrition is an important health problem among this group [7, 9, 12].

Although it has been shown that the Fulani eat little, restricting caloric expenditure to about $1700 \mathrm{kcal} /$ day for male adults and $1540 \mathrm{kcal} /$ day for female adults [11], it was observed that, food habits and diets are changing particularly among nomadic Fulani in south western Nigeria. Dairy products, nuts, and fruits are losing their dominance in the diets of sedentary Fulani as roots and tubers products are becoming increasingly dominant in their diet compared to their nomadic counterpart. Sedentary Fulani are increasing their consumption of rice, cassava, yam, wheat, bread, soft drinks, canned and processed foods. It appears that sedentarization may have opened up new challenges for nomadic Fulani, such as the increasing need for cash income to meet day to day requirements of sedentary living. This has made it compelling for the Fulani to sell most of their dairy and milk products to members of host communities which are not too far from the Fulani settlements. Sale of dairy and milk products are usually assigned to female members while the male member goes grazing with the herds. This has resulted in less availability of dairy and milk products for their children. These findings support other studies where starch was replacing milk in the diets of sedentary

pastoralists in northern Kenya [13]. It is then likely that the reduction in the intake of milk products may be of the factor responsible for the high levels of malnutrition among the Fulani children in this study. These developments have implications for the nutritional status and health of pastoral Fulani populations in southwest Nigeria. Contrary to the widely held assumption that settlement of nomadic pastoral Fulani's in grazing reserves will result in better nutrition, health and living conditions, studies else-where in Kenya among settled pastoralist revealed that settlement diminished nutritional status [14]

In our study, out of the 331 pastoral children assessed, $38.7 \%$ were stunted, $38.7 \%$ underweight and $13.6 \%$ wasting. Since we did not assess children of fully nomadic Fulani children for comparison as these groups are not found in southwest Nigeria, it is difficult to determine if the levels of malnutrition observed were due solely to change in food habits or as a result of other factors. Our study did however, point to the fact that the change in food types and habits may have compromised the normally high protein diet often associated with the pastoral Fulani [11]. It is also suggested that sedentary lifestyle may be a contributory factor to changes in food habits, as this

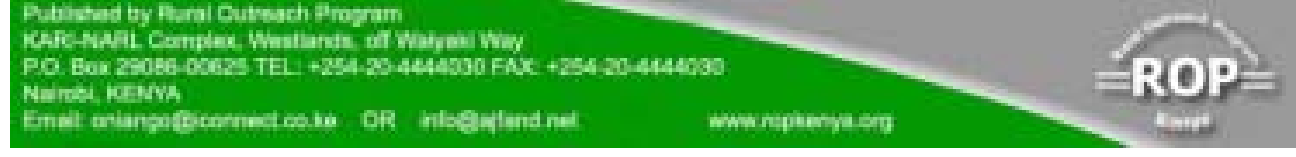


is supported by studies elsewhere, where, for instance among the children of settled and nomadic Rendille in Kenya, malnutrition was three times higher in the settled children [15]. Similarly, the percentage of children with severe and moderate malnutrition was four times less among nomads and pastoralists than among their settled counterpart in Somalia [6]. Of recent, a study in Chad showed that there was more malnutrition in settled pastoralist than their nomadic group [16].

There was no gender variation in the level of malnutrition suggesting that both sexes were exposed to same conditions of nutrition and dietary intake. However, there were variation in nutritional indicators between age groups for stunting (HAZ) and underweight (WAZ) indicating that, as settled Fulani children grew older, they are likely to become stunted and underweight.

Another possible factor for increasing malnutrition of settled Fulani children may be the mode of their settlements. The Fulani lives in clusters of isolated settlements called "Gaa" with housing made up of mud and grass roofing. Boys who are of age are made to follow the herd from dawn to dusk with little food over long distances and difficult grazing terrains, while girls often hawk dairy products over long distances, to bring in cash for the family. The settlements are located very far from health care services that can provide health and nutrition education [3].

Other nutritional indicators not assessed in this study but are also important variables were iron and vitamin A deficiencies. Iron deficiencies have been reported among women and children of Kenyan Turkana and Somali semi-nomads [17]. Likewise, night blindness, probably due to vitamin A deficiency, was found among Fulani of Mali at the end of the dry season when milk production was lowest [18]. There is, therefore, the need to undertake a more comprehensive and in-depth analysis of nutrition and health of semi-nomadic and settled Fulani children populations. Such studies become necessary particularly as there is growing number of Fulani settlements in Southwest Nigeria. Sedentary lifestyle is gradually becoming acceptable to the modern nomadic Fulani not as a way of improving the pastoral production system in Nigeria, but because it offers new economic opportunities, such as trading, farming and small scale enterprises [1-3]. For now, the use of food supplements and aggressive nutritional education by local health workers to the Fulani settlements are necessary to reduce the current levels of malnutrition of nomadic Fulani children.

\section{CONCLUSION}

Findings from this study have important implications for nutrition and growth of pastoral Fulani children settled in a remote and easily inaccessible area in south western Nigeria and indeed in other parts of Southern Nigeria. A large proportion of malnutrition among the pastoral Fulani children reported in this study was due to changing food habits caused by pressure of changes from a nomadic to a sedentary lifestyle. 
The first step in the improvement of nutrition among this population would be to promote the use of food supplements and aggressive nutritional education for the pastoral Fulani. The programme should incorporate specific strategies such the recruitment and training of pastoral member as community health workers for pastoral settlements, integration of Fulani settlements into host communities, so that they can benefit from nutritional and health education programmes. Improve access to water and health care services for these disadvantage groups.

Finally, it would be unwise to think that the southward movement and sedentarization among pastoral populations in Nigeria will soon disappear in response to the hostility and pressures by some host communities. It is a major structural phenomenon that is almost certainly here to stay. How bad or how good the development turns out to be for the entire population will depend on how the Federal and State governments in Nigeria choose to handle the problems and inherent dynamic economic potentials of emerging population composition.

\section{ACKNOWLEDGEMENT}

The authors wish to thank the nomadic Fulani's population of the three states, for their willingness to present their children for measurement. The study was funded by the Wellcome Trust, UK Project Grant No: 069011MA on Health consequences of lifestyle changes among pastoral populations in southwest Nigeria. 


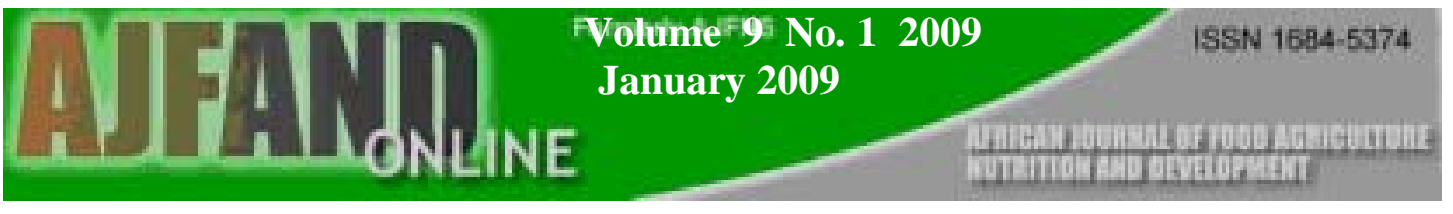

Table1: Summary of nutritional indicators (Z-scores)

\begin{tabular}{lrrr}
\hline & $\begin{array}{l}\text { Height-for-age } \\
\text { HAZ } \\
\text { (Stunting) }\end{array}$ & $\begin{array}{l}\text { Weight-for-age } \\
\text { WAZ } \\
\text { (Underweight) }\end{array}$ & $\begin{array}{l}\text { Weight-for- } \\
\text { height } \\
\text { WHZ (Wasting) }\end{array}$ \\
\hline Overall & & & 331 \\
No. Examined & 331 & 128 & 310 \\
No. below -2 SD & 128 & 38.7 & 45 \\
\% below -2 SD & 38.7 & & 14.5 \\
& & & \\
Sex & & & \\
No.(\%) of Girls below -2 SD & $58(35.4 \%)$ & $56(34.1 \%)$ & $19(11.9 \%)$ \\
No.(\%) of Boys below -2 SD & $70(41.9 \%)$ & $72(43.1 \%)$ & $26(17.2 \%)$ \\
\hline
\end{tabular}


Table 2: Prevalence of low height-for-age (stunting) in nomadic Fulani children, by sex and age group in southwest Nigeria.

\begin{tabular}{|c|c|c|c|c|}
\hline $\begin{array}{l}\text { Age Group } \\
\text { (months) }\end{array}$ & Sex & $\begin{array}{l}\text { Number below } \\
\text { Cut-off (-2 SD) }\end{array}$ & $\begin{array}{l}\text { Number in age } \\
\text { Group }\end{array}$ & $\begin{array}{l}\text { Percentage below } \\
\text { Cut-off }\end{array}$ \\
\hline \multirow{3}{*}{$6-23.99$} & Boys & 12 & 15 & 80.0 \\
\hline & Girls & 9 & 12 & 75.0 \\
\hline & Combined & 21 & 3 & 77.8 \\
\hline \multirow[t]{3}{*}{ 24-35.99 } & Boys & 2 & 2 & 100.00 \\
\hline & Girls & 6 & 17 & 35.3 \\
\hline & Combined & 8 & 19 & 42.1 \\
\hline \multirow[t]{3}{*}{$36-47.99$} & Boys & 9 & 16 & 56.3 \\
\hline & Girls & 2 & 10 & 20.0 \\
\hline & Combined & 11 & 26 & 42.3 \\
\hline \multirow[t]{3}{*}{$48-59.99$} & Boys & 3 & 15 & 20.0 \\
\hline & Girls & 6 & 16 & 37.5 \\
\hline & Combined & 9 & 31 & 29.0 \\
\hline \multirow[t]{3}{*}{$60-71.99$} & Boys & 10 & 17 & 58.8 \\
\hline & Girls & 2 & 9 & 22.2 \\
\hline & Combined & 12 & 26 & 46.2 \\
\hline \multirow{3}{*}{$72-83.99$} & Boys & 4 & 22 & 18.2 \\
\hline & Girls & 6 & 17 & 35.3 \\
\hline & Combined & 10 & 39 & 25.6 \\
\hline \multirow[t]{3}{*}{$84-95.99$} & Boys & 5 & 13 & 38.5 \\
\hline & Girls & 1 & 25 & 4.0 \\
\hline & Combined & 6 & 38 & 15.8 \\
\hline \multirow[t]{3}{*}{ 96-107.99 } & Boys & 9 & 18 & 50.0 \\
\hline & Girls & 1 & 15 & 6.7 \\
\hline & Combined & 10 & 33 & 30.3 \\
\hline \multirow[t]{3}{*}{$108-119.99$} & Boys & 1 & 7 & 14.3 \\
\hline & Girls & 9 & 15 & 60.0 \\
\hline & Combined & 10 & 22 & 45.5 \\
\hline \multirow[t]{3}{*}{$>120$} & Boys & 15 & 42 & 35.7 \\
\hline & Girls & 16 & 28 & 57.1 \\
\hline & Combined & 31 & 70 & 44.3 \\
\hline \multirow[t]{3}{*}{ Total } & Boys & 70 & 167 & 41.9 \\
\hline & Girls & 58 & 164 & 35.4 \\
\hline & Combined & 128 & 331 & 38.7 \\
\hline
\end{tabular}




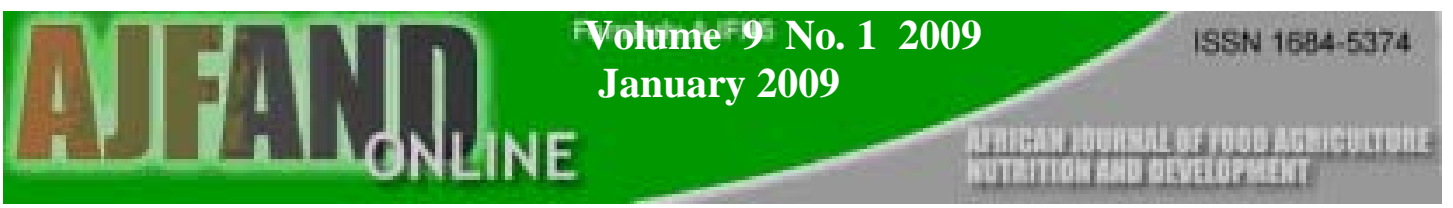

Table 3: Prevalence of low weight-for-age (underweight) in nomadic Fulani children, by sex and age group in southwest Nigeria.

\begin{tabular}{|c|c|c|c|c|}
\hline $\begin{array}{l}\text { Age Group } \\
\text { (months) }\end{array}$ & Sex & $\begin{array}{l}\text { Number below } \\
\text { Cut-off (-2 SD) }\end{array}$ & $\begin{array}{l}\text { Number in age } \\
\text { Group }\end{array}$ & $\begin{array}{l}\text { Percentage below } \\
\text { Cut-off }\end{array}$ \\
\hline \multirow[t]{3}{*}{$6-23.99$} & Boys & 10 & 15 & 66.7 \\
\hline & Girls & 9 & 12 & 75.0 \\
\hline & Combined & 1 & 3 & 70.4 \\
\hline \multirow[t]{3}{*}{ 24-35.99 } & Boys & 2 & 2 & 100.00 \\
\hline & Girls & 6 & 17 & 35.3 \\
\hline & Combined & 8 & 19 & 42.1 \\
\hline \multirow[t]{3}{*}{$36-47.99$} & Boys & 3 & 16 & 18.8 \\
\hline & Girls & 3 & 10 & 30.3 \\
\hline & Combined & 6 & 26 & 23.1 \\
\hline \multirow[t]{3}{*}{$48-59.99$} & Boys & 3 & 15 & 20.0 \\
\hline & Girls & 2 & 16 & 12.5 \\
\hline & Combined & 5 & 31 & 16.1 \\
\hline \multirow[t]{3}{*}{$60-71.99$} & Boys & 5 & 17 & 29.4 \\
\hline & Girls & 1 & 9 & 11.1 \\
\hline & Combined & 6 & 26 & 23.1 \\
\hline \multirow[t]{3}{*}{$72-83.99$} & Boys & 8 & 22 & 36.4 \\
\hline & Girls & 8 & 17 & 47.1 \\
\hline & Combined & 16 & 39 & 41.0 \\
\hline \multirow[t]{3}{*}{ 84-95.99 } & Boys & 5 & 13 & 38.5 \\
\hline & Girls & 1 & 25 & 4.0 \\
\hline & Combined & 6 & 38 & 15.8 \\
\hline \multirow[t]{3}{*}{ 96-107.99 } & Boys & 12 & 18 & 66.7 \\
\hline & Girls & 4 & 15 & 26.7 \\
\hline & Combined & 16 & 33 & 48.5 \\
\hline \multirow{3}{*}{$108-119.99$} & Boys & 1 & 7 & 14.3 \\
\hline & Girls & 10 & 15 & 66.7 \\
\hline & Combined & 11 & 22 & 50.0 \\
\hline \multirow{3}{*}{$>120$} & Boys & 23 & 42 & 54.8 \\
\hline & Girls & 12 & 28 & 42.9 \\
\hline & Combined & 35 & 70 & 50.0 \\
\hline \multirow[t]{3}{*}{ Total } & Boys & 72 & 167 & 43.1 \\
\hline & Girls & 56 & 164 & 34.1 \\
\hline & Combined & 128 & 331 & 38.7 \\
\hline
\end{tabular}


Table 4: Prevalence of low weight-for-height (wasting) in nomadic Fulani children, by sex and age group in southwest Nigeria.

\begin{tabular}{|c|c|c|c|c|}
\hline $\begin{array}{l}\text { Age Group } \\
\text { (months) }\end{array}$ & Sex & $\begin{array}{l}\text { Number below } \\
\text { Cut-off (-2 SD) }\end{array}$ & $\begin{array}{l}\text { Number in age } \\
\text { Group }\end{array}$ & $\begin{array}{l}\text { Percentage below } \\
\text { Cut-off }\end{array}$ \\
\hline \multirow{3}{*}{$6-23.99$} & Boys & 4 & 15 & 26.7 \\
\hline & Girls & 1 & 12 & 8.3 \\
\hline & Combined & 0 & 3 & 18.5 \\
\hline \multirow[t]{3}{*}{ 24-35.99 } & Boys & 0 & 2 & 0.0 \\
\hline & Girls & 4 & 17 & 23.5 \\
\hline & Combined & 4 & 19 & 21.1 \\
\hline \multirow[t]{3}{*}{$36-47.99$} & Boys & 1 & 16 & 6.3 \\
\hline & Girls & 0 & 10 & 0.0 \\
\hline & Combined & 1 & 26 & 3.8 \\
\hline \multirow[t]{3}{*}{$48-59.99$} & Boys & 3 & 15 & 20.0 \\
\hline & Girls & 1 & 16 & 6.3 \\
\hline & Combined & 4 & 31 & 12.9 \\
\hline \multirow[t]{3}{*}{$60-71.99$} & Boys & 0 & 17 & 0.0 \\
\hline & Girls & 2 & 9 & 22.2 \\
\hline & Combined & 2 & 26 & 7.7 \\
\hline \multirow{3}{*}{$72-83.99$} & Boys & 6 & 22 & 27.3 \\
\hline & Girls & 4 & 17 & 23.5 \\
\hline & Combined & 10 & 39 & 25.6 \\
\hline \multirow[t]{3}{*}{$84-95.99$} & Boys & 5 & 13 & 38.5 \\
\hline & Girls & 0 & 25 & 0.0 \\
\hline & Combined & 5 & 38 & 13.2 \\
\hline \multirow[t]{3}{*}{ 96-107.99 } & Boys & 3 & 18 & 16.7 \\
\hline & Girls & 3 & 15 & 20.0 \\
\hline & Combined & 6 & 33 & 18.2 \\
\hline \multirow[t]{3}{*}{$108-119.99$} & Boys & 0 & 7 & 0.0 \\
\hline & Girls & 3 & 15 & 20.0 \\
\hline & Combined & 3 & 22 & 13.6 \\
\hline \multirow[t]{3}{*}{$>120$} & Boys & 4 & 26 & 15.4 \\
\hline & Girls & 1 & 23 & 4.3 \\
\hline & Combined & 5 & 49 & 10.2 \\
\hline \multirow[t]{3}{*}{ Total } & Boys & 26 & 151 & 17.2 \\
\hline & Girls & 19 & 159 & 11.9 \\
\hline & Combined & 45 & 310 & 14.5 \\
\hline
\end{tabular}




\section{REFERENCES}

1. Omotayo AM, Adu IF and ABJ Aina The evolving sedentary lifestyle among nomadic pastoralists in Southwest Nigeria: Implications for land use policy. In.t J. Sustain. Dev. World Ecol. 1999; 6: 1-9.

2. Omotayo AM A land-use system and the challenge of sustainable agropastoral production in southwestern Nigeria. Int. J. Sustain. Dev. World. Ecol. 2002; 9: 369-382.

3. Omotayo AM Ecological implications of Fulbe pastoralism in south western Nigeria. Land Degrad. Dev. 2003; 14: 445-457.

4. Swift J, Toulmin C and S Chatting Providing services for nomadic people A review of the literature and annotated bibliography. In UNICEF staff working papers number 8, UNICEF, New York. 1990.

5. Galvin KA Nutritional Ecology of Pastoralists in Dry Tropical Africa. Am. J. Hum. Biol. 1992: 4: 209-221.

6. Shiek-Mohammed A and JP Velema Where health care has no access: the nomadic populations of sub-Saharan Africa. Trop. Med. Int. Health 1999; 4: 695-707.

7. Glew RH, Conn CA, Bhanji R, Calderon P, Barnes C and DJ VanderJagt Survey of the growth characteristics and body composition of Fulani children in a rural hamlet in northern Nigeria. J. Trop. Paediatr. 2003; 49(5): 313-322.

8. United Nations Summary procedures how to weigh and measure children. In: Assessing the nutritional status of young children in household surveys. New York: United Nations, 1986: 1-11.

9. Glew RH, Brock HS, VanderVoort J, Agaba P, Harkins MS and DJ VanderJagt Lung function and nutritional status of semi-nomadic Fulani children and adolescents in northern Nigeria. J. Trop. Paediatr. 2004; 50(1): 20-25.

10. Hamill PVV, Drizd TA, Johnson CL, Reed RB, Roche AF and WM Moore Physical growth: National Centre for Health Statistics percentiles. Am. J. Clin. Nutr. 1979; 32: 607-629.

11. Glew RH, Williams M, Conn CA, Cadena SM, Crossey M, Okolo SN and DJ VanderJagt Cardiovascular disease risk factors and diet of Fulani pastoralist of northern Nigeria. Am. J. Clin. Nutr. 2001; 74: 730-36. 
12. Glew RH, Conn CA, Bhanji R, Calderon P, Barnes C and DJ VanderJagt Effects of displacement from ethnic/religious conflict on the growth and body composition of Fulani children in Northern Nigeria. J. Trop. Paediatr. 2003; 49(5): 279-285.

13. Fujita M, Roth EA, Nathan MA and EM Fratkin Sedentism, seasonality, and economic status: A multivariate analysis of maternal dietary and health statuses between pastoral and agricultural Ariaal and Rendille communities in northern Kenya. Am. J. Phys. Anthropol. 2004; 123(3): 277-291.

14. Shell-Duncan B and WO Obiero Child nutrition in the transition from nomadic pastoralism to settled lifestyles: individual, household, and community-level factors. Am. J. Phys. Anthropol. 2000; 113(2): 183-200.

15. Nathan MA, Fratkin EM and A Roth Sedentism and child health among Redille pastoralists of Northern Kenya. Soc. Sci. Med. 1996; 43(4): 503-515.

16. Schelling E, Daoud S, Daugla DM, Diallo P, Tanner M and J Zinsstag Morbidity and nutrition patterns of three nomadic pastoralist communities of Chad. Acta Trop. 2005; 95(1):16-25.

17. Murray MJ, Murray AB, Murray MB and CJ Murray The adverse effect of iron repletion on the course of certain infections. BMJ. 1978: 2: 1113-1115.

18. Hilderbrand $\mathbf{K}$ Assessing the components of seasonal stress amongst Fulani of the Senomango, Central Mali. In: Hill AG (Ed). Population, Health and Nutrition in the Sahil, Routledge and Kegan Paul, London, 1985: 254-287. 